\section{Train Times, Irish Whiskey, Bad Weather, Potage and Poldhu}

\begin{abstract}
Guglielmo Marconi and the events leading up to the first transatlantic radio message by $\mathbf{R} \mathbf{W}$ Simons, Marconi researcher, 1943-1986
\end{abstract}

Marconi was born in Bologna, Italy, on 25 April 1874. He was the second son of a runaway marriage between Giuseppe Marconi, the son of a wealthy landowner, and Annie Jameson, daughter of Andrew Jameson of the Irish Whiskey Company.

Marconi was initially educated, between the ages of five and seven, at a private school in Bedford, UK. He went to school in Florence up to the age of 14 and then for two years at the Leghorn Lyceum (Livorno). He also received extra private instruction in science. Despite this, however, he did not gain the qualifications needed to enter either the University at Bologna, or the Naval Academy.

At the age of 18 , after he had passed the examination that allowed him to delay his compulsory military service until the age of 26, he attended lectures at Bologna University, some by a tutor called Righi, by special arrangement.

During 1894 (aged 20) he studied the works of Heinrich Hertz (who had died that year). This interest was probably prompted by a commemorative article written by Righi, having previously become familiar with the mathematical conclusions of James Clerk Maxwell and Lord Kelvin. He had also read a description of the results obtained (by
Branly), with detectors consisting of imperfect electrical contacts.

Marconi started his experiments on the application of Hertzian waves to the transmission and reception of messages over a distance, without wires, in the early summer of 1895 at the Villa Grifone at Pontecchio Bologna.

He clearly began by repeating the experiments of Hertz, but unfortunately there are no detailed records or notes of the steps that he took to improve the performance of his apparatus, so that transmission and reception of signals was progressively possible across a room, down the length of a corridor, and from the house into the fields. Success was signalled initially by the waving of a handkerchief, and progressed to the need to fire a gun in order to indicate reception at a distance of about two kilometres, out of sight over an adjacent hill, in September of that year.

Although no notes exist, many anecdotes refer extensively to his intense dedication to achieving a successful and improved system. He was clearly a great experimenter, who, if he lacked a scientific means of pointing the way forward, would, by a great many iterations, obtain an optimum solution.

For example, he started transmitting

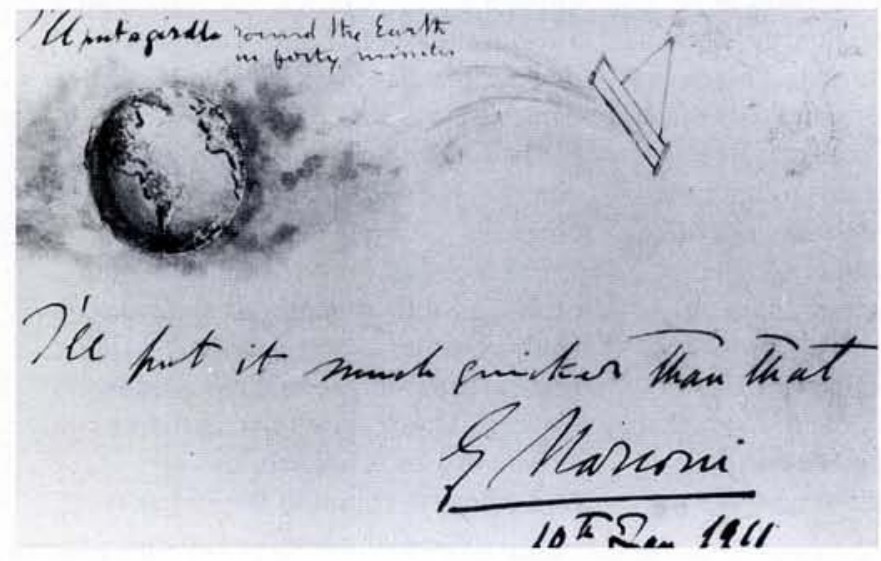

Fig 1 Marconi quotes Shakespeare: I'll put a girdle round the Earth in forty minutes (A Midsummer Night's Dream, Act 2 Scene 1), and adds: I'll put it much quicker than that. In his desire to communicate over ever larger distances - he wanted to send global messages - no challenge was too great for Marconi with the short dipoles and sheet reflectors of Hertz, connected to a battery powered induction coil. A next step was to leave the spark gap at ground level and to raise the arms of the dipole above ground or alternatively one arm to a plate on (or in) the ground and the other to a plate on a pole. Both methods were used in subsequent demonstrations. He had made a modified Hertz oscillator, but one with much greater capacitance and hence greater radiating power.

Clearly his inventive and intuitive ability was applied to the receiver (fig 2) which consisted essentially of a coherer connected to a similar aerial arrangement to that used by the transmitter ( fig $_{3}$ ) and then to a conventional relay and inker system, borrowed from telegraphy equipment. Marconi's coherer seems to have been derived from Branly, but Popov - the description of Marconi as 'the Father of Wireless' is attributed to Aleksandr Popov (1859-1906), the contemporary Russian Scientist, who was one of the many people studying the work of Hertz in the latter part of the last century - had used a very similar type for the recording of lightning strikes in 1893 . There were many versions of basically the same design, where filings of metal were held between metal plugs in a tube (fig 4 ).

The precise theory of operation of the coherer has never been determined, but it can be regarded as a device with a specially-constructed 'dry joint' which has two states: one of high resistance and the other of very low resistance. It has the characteristic that the application of an RF signal will change it from the high to low resistance state, where it will stay until mechanically shaken.

It is said that Marconi tried several hundred combinations of metal filings of various sizes between metal plugs of different shapes and spacings before settling on undoubtedly a very refined version. Marconi's tube (which was evacuated) was small, (about $50 \mathrm{~mm}$ long), the gap between the slightly tapered silver plugs was also small ( 0.635 $\mathrm{mm}$ ) and the faces had been treated with mercury. He used $95 \%$ nickel mixed with $5 \%$ silver, for the filings.

There is an apocryphal story about the experience of H.M. Dowsett (who was to become the Technical General Manager of The Marconi Company in 1931) on his first day in 1899. Marconi gave him an old smooth file and a small piece of metal and told him to make some filings. After half an hour he had only made a very 
small heap and was convinced that as the 'new boy', he was having his leg pulled. However, Marconi subsequently told him that he had produced one coherer's-worth of filings and that only a clogged-up file would produce small enough particles.

Even at this early stage, Marconi had showed that he was very capable of developing his concepts and apparatus to a high level of performance and reliability, and he started to relate the performance to the parameters of his equipment. He discovered, as a result of many iterations, that the distance over which signals could be transmitted and received, varied in proportion to the square of the length of the vertical wires attached to the transmitter and receiver. Furthermore he found that when plates were attached to the top of the wires, the range varied in proportion to the square of the height of these plates from the earth. Probably the plates were not themselves so important, but the increase in capacitance was. Marconi referred to this relationship with height in his Nobel Prize Speech in 1909. A $2 \mathrm{~m}$ pole gave a range of $30 \mathrm{~m}$, a $4 \mathrm{~m}$ pole $100 \mathrm{~m}$ and an $8 \mathrm{~m}$ pole a range of $400 \mathrm{~m}$.

He also showed at that time and many times later, as is evident from his numerous patents, that 'improvements to design' was a continuous process - for example, putting the receiver in a metal box to avoid spurious interference to the recording equipment caused by the transmitter, a means that would be obvious today.

Similarly, automatically disconnecting the receiver aerial by using a back contact on the sending Morse key was another improvement, known as the 'grasshopper' key.

In January 1896 , less than a year after he had started experimenting seriously, he was considering applying for a patent

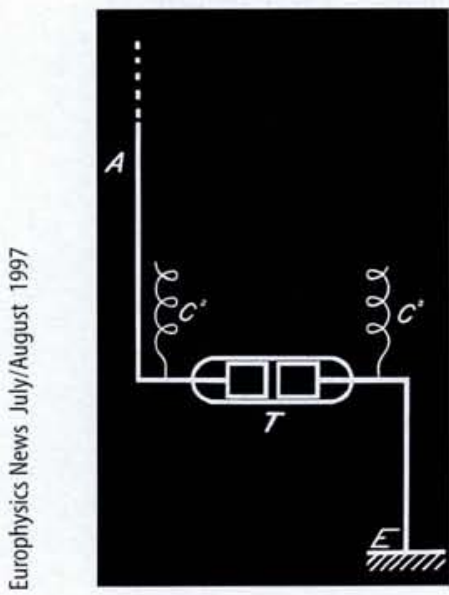

Fig 2

A diagram of an early receiver, taken from a slide used in Marconi's lecture to the Royal Society of Arts, UK in 1901 for his invention. But prior to so doing, he offered to make the information available to the Italian Government. He did so via a family friend, General Ferrero, who was the Italian Ambassador to London. Marconi came to London in the middle of February 1896 with his mother and called on the Ambassador. Unfortunately, Marconi's 'Black Box' had been broken by the Customs in the course of their examination of this unfamiliar apparatus.

After many months of consideration, the Italian Government advised Marconi to make his inventions available worldwide and British Patent 12039 was filed on 2 June 1896 - the first wireless telegraphy patent. The patent includes the words: 'I believe that I am the first to discover and use any practical means for effective telegraphic transmission and intelligible reception of signals produced by artificially-formed Hertz oscillations.'

\section{Patent 12039}

The description in the patent papers is a very complete practical disclosure, with layout diagrams. The claims cover the use of a keyed induction coil producing sparks across a gap, one or both sides of which may be connected to elevated plates or wires. One rather unusual item to find in the patent is the use of a rotating contact driven by an electric motor to keep the trembler contacts smooth and without a tendency to stick just another improvement. Alternatively one side of the transmitter may be earthed and the other side connected to a plate or wire. Similarly for the receiver, with the spark gap replaced by a coherer. There are many claims for the coherer and the tapper and the method of connection using chokes.

It was Marconi's cousin, Henry Jameson-Davis, who met the Marconi family when they arrived in London and it was Jameson-Davis who introduced Marconi to A.A. Campbell-Swinton who, having seen a demonstration, gave him a Letter of Introduction to W.H. Preece, the Chief Engineer of the British Post Office, in June 1896 . In July of that year he demonstrated his apparatus to both the Post Office and the War Office, and there was a further historic demonstration at Three Mile Hill on Salisbury Plain on 2 September, with the General Post Office, the Navy and the Army present. This demonstration worked at $2 \mathrm{~m}$ wavelength. The service representatives were, even at this time, concerned with the security of communication.

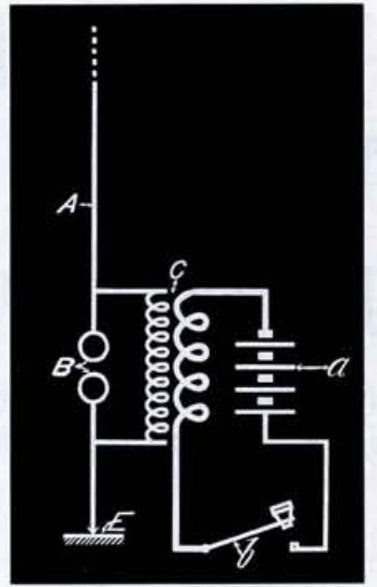

Fig 3

Early transmitter

The Naval observer on Salisbury Plain was Captain H. Jackson, who, in that same year, had succeeded in communicating between ships, using equipment similar to Marconi's, but totally independently. An Army observer, Major Carr, was impressed and, as a result, Marconi was asked to develop apparatus that would activate a receiver in a steel box immersed in the sea, a mile off shore, to detonate mines remotely. (This was not followed up.)

William Preece, assisted by Marconi, gave an important lecture at Toynbee Hall on 12 December 1896 . The Press who attended, headlined Marconi as 'the inventor of wireless'. This description prompted a strong reaction from scientific circles and Oliver Lodge, who also had made valuable contributions, was outraged.

Lodge had shown to a meeting of the Royal Institution on 1 June 1894 , and in the same year at Oxford, that his form of a Branly detector could detect signals at $140 \mathrm{~m}$. He did not however appear to have grasped the significance of this demonstration and had not extrapolated from his experiments to a form of practical long-distance telegraphy.

Lodge said later (1897): 'Stupidly enough, no attempt was made to apply any but the feeblest power so as to test how far the disturbance could really be detected.'

Ernest Rutherford, using a magnetic detector, had also signalled acrosss $800 \mathrm{~m}$ of streets in Cambridge, in June 1896.

In 1895-1896, Popov, Rutherford and others, used these methods applied to the study of atmospheric electricity, using vertical rods similar to those used by Marconi. Popov's use of an aerial was only as part of a receiver, with no transmission. Popov, in December 1895, said: 'I hope that when my apparatus is 
perfected, it will be applicable to the transmission of signals to a distance...when a sufficiently powerful generator of these vibrations is discovered.' He did not really need more power, but a more sensitive detector.

One comment made by Preece during his lecture, which was not borne out, was that the Post Office had decided to spare no expense in experimenting with the apparatus, and one of the first trials would be from Penarth to an island in the (Bristol) Channel. This was the path used by Preece for his induction experiments. The trials took place, but no money came from the Post Office.

Preece went on to say that he had the greatest faith in the apparatus: 'The curious thing about it is that there is no new principle introduced. The first man who taught us how to generate these waves was Hertz, and they have been developed by others, but in making practical use of these waves, Mr. Marconi has invented devices which are highly novel and very beautiful, and when they are patented and can be made public, I think they will be admired by everybody.'

Marconi did not claim novelty, only improvements, these improvements were the subject of the 12039 patent. 'My invention relates in great measure to the manner in which the above apparatus is made and connected together.' Nothing false was ever claimed by either Marconi or Preece.

More experiments continued in the following year (1897) with the assistance of Preece, with whom Marconi remained a great friend for years, although Preece sometimes had to take a formal position because of his Post Office appointment.

Although Marconi did not like public speaking, he gave lectures at the Royal Institution, The Royal Society of Arts, the Institution of Electrical Engineers, all in the UK, and many other venues, on the progress of his work, any or all of which could have been done by Preece, or many others, but weren't. In March he was back on Salisbury Plain achieving a range of $11 \mathrm{~km}$.

The reports of Jackson to the Commander-in-Chief, Devonport, on both of the Salisbury Plain demonstrations are complete and contain considerable detail of Marconi's equipment. Jackson acknowledged that there was little difference between his and Marconi's apparatus and that the results were similar, although Jackson's were slightly inferior because he had a less powerful transmitter and a less sensitive receiving apparatus.

He commented that the Marconi apparatus consumed $13 \mathrm{~W}$ to transmit over $3 \mathrm{~km}$, whilst the power required for a ship's mast-head lamp was $260 \mathrm{~W}$.

He was, however, the recorder of the reported remark that, 'there is no possible market for the instrument, except for naval and military purposes.' Who actually said this is not clear.

\section{Train Times}

George Kemp was very active as Marconi's assistant ( fig 6). He was an exPetty Officer in the Royal Navy and had been one of Preece's laboratory assistants. He joined Marconi from the Post Office, becoming his assistant and technician for more than thirty years. He kept notebooks of his work and, in the 1930s, prepared further, more complete records. These latter documents are in the Marconi archives. Unfortunately, although his copperplate handwriting gives a general description, there is more detail about the travelling arrangements and times of trains, than of the exact equipment used in the experiments.

There is much more detail available about the trials across the Bristol Channel in May, as Preece presented a lecture on the results at the Royal Institution on 4 June 1897 . These tests were conducted, as usual, in the normal bad weather conditions and the record tells of people

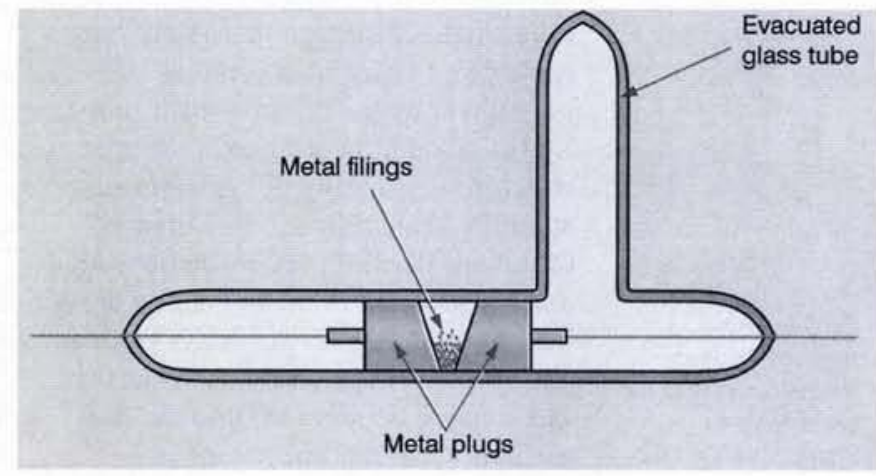

Fig 4 The coherer perhaps the most important of the early detectors huddled in huts on the beach to get out of the storm. No success was achieved on the first two days with the aerial at $46 \mathrm{~m}$, but on the fourth day, with the aerial at $92 \mathrm{~m}$ and using a $0.5 \mathrm{~m}$ spark coil, a new record range of $14 \mathrm{~km}$ was achieved. The Morse message that was sent was: 'Let it be so' (at a wavelength of $1.25 \mathrm{~m}$ ).

During this period, Preece repeated his electromagnetic experiment on 10 May with perfect results.

Among the people who witnessed these tests was Adolf Slaby, scientific adviser to the German Emperor. He commented: 'What I saw was something new; Marconi had made a discovery; he worked with means, the full importance of which had not been recognized and which alone explained the secret of his success. He has thus, first shown, how by connecting the apparatus with the earth on the one side and by using long-extended vertical wires on the other side, telegraphy was possible.'

Slaby suggested therefore that wireless telegraphy was a misnomer and proposed 'spark telegraphy'. 'Die Funkentelegraphie' was the term adopted in Germany.

There were many approaches to buy Marconi's patents and there were rumours that the taxpayer 'was funding him to the detriment of British scientists'.

Once again this was where the whiskey connection was significant because Jameson Davis, his cousin, became the first Managing Director of the Wireless Telegraph and Signal Co. on 20 July 1897. Colonel Jameson Davis was a cornmilling engineer and seven of the eight other first subscribers were corn factors, or corn merchants.

The company name was changed to Marconi's Wireless Telegraph Co. Ltd on 24 March 1900 when Samuel Flood Page became Managing Director. The Marconi International Marine Co. was created on April 25 1900, Marconi's 26th birthday.

With the setting-up of the Company, the number of demonstrations increased significantly. Marconi was in Italy when the Company was being formed and, as a result of this visit, it was announced shortly afterwards that the Italian Navy would adopt Marconi's apparatus.

Later that year, in October, Marconi was back on Salisbury Plain, now communicating with Bath, $54 \mathrm{~km}$ away.

The new Company created a separation with the Post Office, which carried out experiments of its own at Dover, but without much success. The report by Preece to the Post Office on this work, 
said to be for the purpose of 'determining the laws which govern this method of transmission' includes the comment: 'The results at Dover are distinctly unfavourable when compared with those we had between Lavernock and Brean Down in the Bristol Channel'.

Marconi then concentrated on his original idea of communication with, and between, ships at sea. He established a coastal station at the Needles Hotel, Alum Bay, Isle of Wight and carried out tests with two steamers, achieving ranges of up to $129 \mathrm{~km}$ - always, it seems, in bad weather. Bad weather and the results of gales continually appear in the records of Marconi's work.

A second station was set up at the Madeira Hotel, Bournemouth. Lord Kelvin sent the first paid message (he insisted on paying, fig 5), thus creating a problem with the Post Office, whose monopoly covered all messages within the three mile limit.

Towards the end of September 1898, Marconi left the Madeira Hotel because of a dispute with the management over the cost of accommodating the aerial, $35 \mathrm{~m}$ high, in the front garden. He moved to the Haven Hotel at Poole, where he worked and lived from time to time until 1926.

Further demonstrations were given at many places including,

- from the House of Commons across the Thames in London to St. Thomas' Hospital;

- 150 messages sent from Queen Victoria at Osborne House to the Prince of Wales on the Royal Yacht 'Osborne' at a regatta in Cowes;

- from the East Goodwin Lightship to the $\mathrm{N}$. Foreland Lighthouse at a range of $19 \mathrm{~km}$. This link was maintained by the Company for 14 months at its own expense;
- at the America Cup races 1899 , at the request of the New York Herald and Evening Telegram.

Naval manœuvres in 1899 gave the opportunity for communication over a distance of $152 \mathrm{~km}$ using an intermediate ship as a repeater (HMS Europa to HMS Juno to HMS Alexandra), giving that section of the fleet an advantage of about three hours.

Jackson, on HMS Juno, noted that the distance of the horizon from the height of the aerials, $45 \mathrm{~m}$, was $50 \mathrm{~km}$ and that communication between Juno and Europa had been achieved over $96 \mathrm{~km}$. He says: 'The induction must have passed through or over a mass of sea water about 500 feet high and 30 miles thick.' [ $150 \mathrm{~m}$ and 48 $\mathrm{km}]$.

On his return from the USA in the SS St. Paul in 1899, Marconi established contact with the Needles at 60 miles, receiving the latest news of the South African war. The Transatlantic Times, Vol 1, No 1 was produced, dated 15 November 1899 , at $\$ 1$ a copy.

As a result of these and many other trials, Marconi obtained the initial orders for his new Company. However, the Company did not show a profit for several years and if it had not been for the continued financial support from his fellow directors, he would not have been able to continue his experiments and the Company would have failed.

Marconi engaged technical staff, J. Erskine-Murray in 1898 , and W. H. Eccles in 1900. This support gave him a significant advantage over both Oliver Lodge, who had to run a department at Liverpool University, and Jackson, who had to carry out his Naval duties, in addition to their studies of wireless.

In April 1900, the famous 'Four Sevens' patent (patent number 7777) was granted

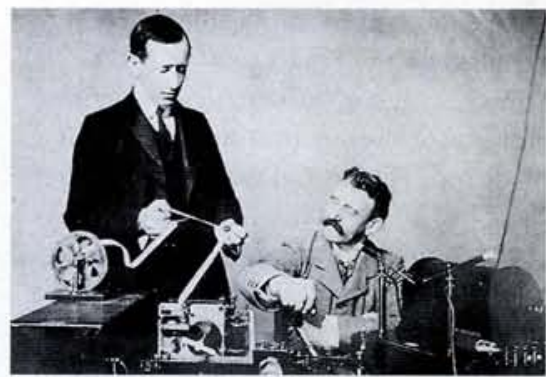

Fig 6 Marconi with George Kemp (seated)

for 'Syntonic Transmission and Reception'. As with the first patent, the novelty consisted not in a new discovery of scientific principle, but in its method of application to the purposes of wireless telegraphy.

The method by which the natural frequency of oscillation of a circuit could be controlled was already known. If a circuit were constructed to be a good radiator of energy (for example an open aerial) the oscillations set up therein by a spark discharge would quickly die away as the energy was dissipated in radiation. Ideally the circuit would maintain the oscillation between each discharge by resonating. Such a circuit could be constructed, but the two requirements of being a good radiator and for sustained resonance were recognized as being mutually conflicting.

By combining within his apparatus two tuned circuits, one being a highly resonant closed circuit and the other an aerial circuit of good radiating characteristics, and weakly coupling the two together, a successful result was obtained, with greater range and selectivity.

The radio frequency transformers were called 'jiggers'. Marconi had effected the practical compromise that allowed control of the rate at which energy was transferred to the aerial.

\section{Poldhu}

It would be a serious oversight to omit reference to the transatlantic experiments, although these were only possible by virtue of enormous investment by the Board of the Company. Ambrose Fleming designed the apparatus at Poldhu, Cornwall,UK having been appointed Scientific Adviser to the Company. Work started in October 1900 and tests started in the beginning of 1901. The input power was $20-25 \mathrm{~kW}$ from an alternator giving $2000 \mathrm{~V}$ at $50 \mathrm{~Hz}$, this was stepped up to $20 \mathrm{kV}$ into a closed oscillating circuit. The keying was message: Lord Kelvin's telegram, sent from the Isle of Wight to Bournemouth in 1898 
achieved by shorting out chokes in the output of the alternator.

It was decided to build a second similar station at Cape Cod but, once again, the weather took an active part and the large inverted cone aerials at both sites were wrecked (figs 7,8 ).

Marconi decided to do a one-way test, by taking a receiver to Signal Hill at St. Johns', Newfoundland. He gave the wavelength of operation as $366 \mathrm{~m}$.

At St. Johns', Marconi and Kemp used a kite to lift the aerial wire to $122 \mathrm{~m}$, but because of the wind the system would not stay in tune and hence the new syntonic receiver was abandoned for a plain aerialto-earth circuit, coupled by a jigger to a circuit containing a mercury coherer (probably operating as a rectifier) with a telephone earpiece in series. The dots were received at 1230 hours on 12 December 1901 local time and recorded in his diary. The weather got worse and the tests could not be continued, preventing confirmation by an independent person.

Immediately after this success and in order to ensure the presence of Marconi, the American Institute of Electrical Engineers brought forward, at very short notice, the date of their Annual Dinner at the Waldorf Hotel and held it in honour of Marconi on January 13th 1902 . The room was decorated with lamps flashing the Morse ' $\mathrm{S}$ ' and the menu (signed by many, including Alexander Graham Bell) had a cover that reflected the transatlantic achievement (one item on the menu was 'Potage Electrolytique').

Subsequently, the Philadelphia, in February 1902, revealed that the range obtainable at night was much greater than at day, achieving $3358 \mathrm{~km}$; the King of Italy placed the new warship Carlo Alberto, with a crew of 800 , at Marconi's disposal enabling him to carry out more experiments, over a period of six months, from Finland, Prussia, the Mediterranean and the North Atlantic coast of America.

A most significant invention of Marconi was the Magnetic Detector, which became the standard system for reception for many years, superseding the coherer. Again, Marconi applied a phenomenon, discovered by Rutherford in 1895 , which was based upon the effect of high frequencies on the magnetic characteristics of iron. The actual operation of the detector was not understood until research into the theory of magnetic materials produced an explanation in 1931.

If we remember that the first person to

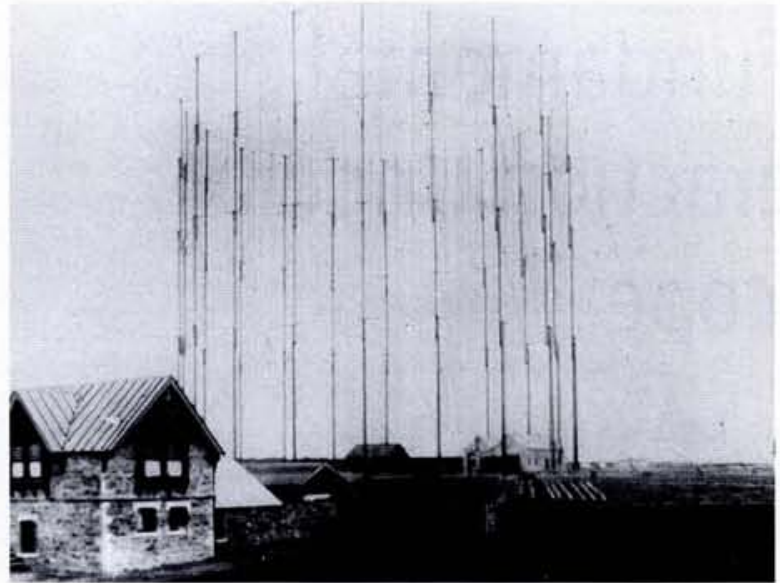

Fig 7 The first inverted-cone aerial, at Poldhu in Cornwall. Marconi was to have sent the first live transatlantic radio message from here, to a receiver on the coast of Newfoundland, in 1901...

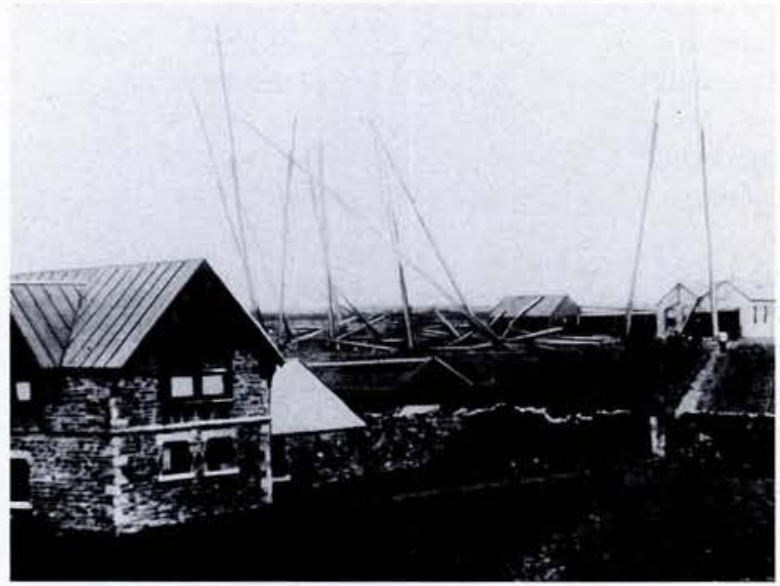

Fig 8 ...but bad weather wrecked the aerial before he had a chance.

notice that the lid of the kettle lifted when the water boiled did not himself design the steam engine, then we can identify the qualities that marked Marconi as the pioneer of wireless. He was not primarily interested in the purely scientific aspects, but in the practical application for useful purposes.

He was also a great predictor. At a meeting of the American Institute of Electrical Engineers on 20 June 1922, he concluded with the following remarks: 'As was first shown by Hertz, electric waves can be completely reflected by conducting bodies. In some of my tests, I have noticed the effects of reflection and deflection of these waves by metallic objects miles away. It seems to me, that it should be possible to design apparatus by means of which a ship could radiate or project a divergent beam of these rays in any desired direction, which rays, if coming across a metallic object, such as another steamer or ship, would be reflected back to a receiver screened from the local transmitter on the sending ship, and thereby immediately reveal the presence and bearing of the other ship in fog or thick weather. One further great advantage of such an arrangement would be that it would be able to give warning of the presence and bearing of ships, even should these ships be unprovided with any kind of radio. I have brought these results and ideas to your notice as I feel and perhaps you will agree with me that the study of short electric waves, although sadly neglected practically all through the history of wireless, is still likely to develop in many unexpected directions, and open up new fields of profitable research.'

He felt that it was his initiative in using longer and longer wavelengths that was responsible for this neglect as everyone followed his preoccupation with increasingly greater wavelengths (Poldhu/Clifden: $1100 \mathrm{~m}$ (1901), $2000 \mathrm{~m}$ (1903), $3660 \mathrm{~m}$ (1904), $6660 \mathrm{~m}$ (1907)).

And in 1927 he said: 'I am known as a man who deals in cold scientific facts and practicalities, not in Utopian fantasies... As to talk of a saturation point, a limit to radio progress, there is no limit to distance, hence there can be no limit to wireless development.' He died in 1937.

This is a shortened version of an article that first appeared in GEC Review 111 1996. Reprinted by kind permission of the editors and the author. Illustrations courtesy of Marconi archives. 